\title{
Narrativas homoeróticas: sexo, amor e família nas páginas dos romances sentimentais
}

\author{
Roberta Manuela Barros de Andrade
}

Universidade Estadual do Ceará, Curso de Ciências Sociais, Fortaleza, CE, Brasil

ORCID: https://orcid.org/0000-0001-8918-2186

\section{Ricardo Augusto de Sabóia Feitosa}

Universidade Federal de Pernambuco, Núcleo de Design e Comunicação, Caruaru, PE, Brasil

ORCID: https://orcid.org/0000-0002-4095-5165

\begin{abstract}
Resumo
O artigo propõe uma análise dos romances sentimentais homoeróticos, investigando-os como dispositivos de elaboração de modelos normativos de relações sexuais e afetivas protagonizadas por personagens homossexuais masculinos. A partir da leitura crítica de três romances representativos desse gênero ficcional, interroga-se a existência de marcas distintivas em tais "romances de amor", as especificidades em suas tramas e em que medida se enquadram ou reforçam as gramáticas que regem essa produção literária de cunho popular. Busca-se compreender, assim, as diferentes configurações discursivas sobre as quais os sentidos do homoerotismo masculino são pensados e problematizados neste espaço ficcional, segmento pouco explorado tanto nos estudos literários como no campo das investigações em gênero e sexualidade.
\end{abstract}

\section{Palavras-chave}

Literatura sentimental; Homoerotismo; Cultura de massa; Normatividade; Masculinidades

\section{Os romances sentimentais homoeróticos}

Os romances sentimentais são comumente criticados pela literatura especializada e marginalizados por grupos pertencentes a diferentes estratos sociais. Centrados em contar histórias de amor, geram, no entanto, um montante expressivo de vendas. Na primeira década do novo milênio, por sua vez, ganham novo impulso com o advento da internet, onde podem ser comprados ou baixados, de forma gratuita, nos diversos sites voltados para o gênero. Em nosso país, identificam-se iniciativas, sem fins lucrativos, comumente autodenominadas de "Projetos de Democratização da Leitura" (PDL), páginas de internet 
idealizadas, organizadas e administradas de forma amadora por fãs do gênero que se utilizam de mão de obra voluntária para efetivar a transcrição, tradução (se for o caso) e circulação de livros de amor entre seus leitores à revelia das suas editoras ${ }^{1}$ (ANDRADE e SILVA, 2018a).

Assim, nos sites e blogs dedicados a estes romances, é possível encontrar tanto sucessos antigos do mercado editorial como também livros estrangeiros que ainda não foram lançados no Brasil e que são traduzidos por estes projetos em versões em português, o que garante o contato do público brasileiro com obras que não foram ainda objeto de interesse das editoras nacionais. Porém, se os livros selecionados para serem disponibilizados se caracterizam, prioritariamente, por contar os encontros e desencontros do amor heterossexual, na primeira década do século XXI, os fãs de romances sentimentais se deparam com um nicho de mercado que se avoluma no mundo inteiro: o da literatura de entretenimento que narra histórias de amor romântico cujo casal protagonista é homossexual.

De fato, na Europa e na América do Norte, as editoras especializadas em literatura sentimental têm investido massivamente nos romances de temática gay, abrindo um nicho de mercado que se expande a cada dia, como pode ser atestado por uma rápida visita a qualquer site de vendas nesses continentes. Essa identificação do público leitor internacional com a literatura sentimental gay ampliou, nas últimas duas décadas, o foco de interesse do mercado na sua popularização, chegando ao Brasil, no circuito oficial, pelas livrarias, físicas ou virtuais, disponíveis no mercado.

No entanto, redes de livrarias como Cultura, Saraiva e Amazon oferecem, quase em sua totalidade, somente romances sentimentais gays em língua estrangeira e, ainda assim, a oferta não passa de uma dezena de exemplares. As editoras nacionais não parecem ainda ter grande interesse neste nicho. Todavia, no Brasil, o seu consumo está disponível através de comunidades de fãs que realizam a tradução e circulação dessas obras de forma gratuita. A

\footnotetext{
1 Os projetos de democratização da leitura, em geral, iniciativas de órgãos públicos, baseiam- se na difusão de obras cujos direitos de publicação foram cedidos por seus autores ou cujos direitos autorais já caducaram. Entrementes, decidimos nomear estes projetos como pertencentes a esta categoria porque estes se denominam como tais, apesar de nem sempre trabalharem com livros livres de direitos de publicação. De qualquer forma, abstraindo as questões legais, o intuito é o mesmo: facilitar o contato com os livros deste gênero, cujo acesso, por questões econômicas, ainda é interditado à grande maioria da população brasileira. Há, pelo menos, dez grandes projetos em andamento: o "Projeto Revisoras e Projeto Revisoras Traduções", o "Projeto Romances", o "Livros Florzinhas”, o "Prazer em Seduzir", o "Livros Corações”, o "E-books Românticos e Eróticos", o "Adoro Romances em E-Books ou ARE”, “Grupo Hot Manias", a “Comunidade ARS”, o "Tiamat World" e o "Romance com Tema Sobrenatural”. Os livros oriundos destes projetos são baixados em vários blogs voltados para o tema, ao mesmo tempo que podem ser encontrados em páginas de arquivamento de suportes eletrônicos.
} 
esta literatura, para fins desse trabalho, denominamos de romances sentimentais homoeróticos ${ }^{2}$.

Não se trata, para fins desta pesquisa, porém, de enfocar a literatura de temática gay ou homoerótica de orientação engajada representada por variadas editoras estrangeiras mundo afora cujos desdobramentos, em especial, a partir da última década, se encontram no mercado brasileiro nas editoras $\mathrm{LGBT}^{3}$, ou ainda de romances de autoras e autores reconhecidos em circuitos (editoras, revistas especializadas, pesquisas acadêmicas) literário ou acadêmico. Sobretudo, ressaltamos que parte desta literatura, viabilizada nas editoras LGBT, tem como diretriz o testemunho, a reivindicação, a militância, a conscientização visando a elaborar ou a dar mais visibilidade a demandas das minorias; diminuir o preconceito e levar informação a um público leitor segmentado (DIAS, 2013). Porém, os romances sentimentais em destaque estão prioritariamente inseridos em relações mercadológicas, seu público é amplo ${ }^{4}$ e, como demonstraremos, estão longe de promover relações emancipadoras em seu discurso. Ao contrário de muitas obras oriundas dessa literatura engajada, os romances sentimentais homoeróticos não são autobiográficos nem ousam adentrar em uma estética específica.

Nem tampouco pretendemos, aqui, penetrar na profícua seara dos Estudos Literários e/ou Culturais que elegeram como objeto de análise os clássicos de nossa literatura nacional que abordam, em suas narrativas, de forma sutil ou mais escancarada, o homoerotismo 5 . Neste universo, destacam-se como objeto de escrutínio da literatura homoerótica obras de nossa literatura canônica como O Ateneu (1888), de Raul Pompéia, O Cortiço (1890), de Aluísio de Azevedo e $O$ Bom Crioulo (1895), de Adolfo Caminha. Na percepção da academia, muitas dessas obras carregam consigo uma condição trágica, uma perversão, um vício, uma condição abjeta que abarcam a concorrência de diversos discursos morais, teológicos, jurídicos e médicos que procuravam dar conta do homoerotismo em fins do século XIX (VALE, 2018, MITIDIERI e CAMARGO, 2015, SOUZA JUNIOR, 2010, PÉRET, 2010).

\footnotetext{
2 Priorizamos o termo homoerótico em detrimento da expressão mais usual literatura gay porque acreditamos que o conceito popularizado por Costa (1992) é mais abrangente, à medida que enfoca diferentes formas de relacionamento erótico entre homens ou mulheres, independentemente das configurações histórico-culturais que assumem e das percepções pessoais e sociais que geram, bem como da presença ou ausência de elementos genitais, emocionais ou identitários específicos (VALE, 2018).

3 Neste universo editorial brasileiro, destacam-se as editoras Brejeiras Malagueta, Edições LGBTTT, Editora Escândalo e Metanoia.

40 fato de esses romances serem traduzidos por projetos de democratização protagonizados por mulheres ao mesmo tempo em que são disponibilizados e comentados em blogs cuja frequência é eminentemente feminina nos leva a crer que uma significativa parcela de seus leitores pertence ao sexo feminino, não tendo, pois, como consumidores, apenas uma audiência homossexual masculina.

5 A temática do homoerotismo constitui-se um dos eixos centrais da literatura ocidental, o que se repete em nossa literatura nativa (BARCELLOS, 2006).
} 
Na literatura sentimental, de cunho popular que abordamos nessa pesquisa, as personagens homossexuais já nasceram em ambientes e sociedades que relativamente as toleram, aceitam e incorporam, distanciada de discursos trágicos, médico-legais ou moralmente reprováveis. Nestas obras, há uma clara "suavização" das questões ditas gays, que só muito tangencialmente aparecem no escopo do texto. Neste sentido, as personagens não carregam consigo o peso do preconceito, da rejeição ou da marginalização. Assim, esta literatura situa-se num contexto de intensa mercantilização das relações homo orientadas, num império de estereótipos de beleza, juventude, consumo e adequação de comportamentos que atravessam tal processo (BARCELLOS, 2006).

A escolha por nos debruçarmos sobre tal objeto pressupõe que o homoerotismo, como toda e qualquer expressão cultural, é construído em contextos literários variados e distintos. Trata-se de uma produção literária, geralmente considerada pela crítica de menor qualidade estética, com um novo nicho: o dos romances sentimentais que trazem como casal protagonista personagens cujas identidades aproximam-se do ideal "gay". A literatura sentimental, em especial a homoerótica, é um gênero que se desvia do foco tanto da literatura canônica como da engajada, portanto, situa-se ainda nas margens e nos bastidores dos estudos acadêmicos ${ }^{6}$, necessitando, pois, ainda de um escrutínio mais contundente.

Nesse contexto, nos indagamos: como a literatura sentimental conhece, reconhece e diz o amor entre estes homens? Como este espaço ficcional descreve, constrói e problematiza suas personagens, enredo e cenários? Como o surgimento do homoerotismo no interior da literatura sentimental reafirma, transforma ou hibridiza as normas e regras desse gênero? A literatura sentimental homoerótica constitui um novo padrão estético ou apenas reafirma os parâmetros heteronormativos da tradição patriarcal e falocêntrica recorrentes neste segmento editorial?

Assim, nosso objetivo é investigar as estratégias discursivas através das quais a literatura sentimental procura conhecer, reconhecer e dizer o que ela preconiza como relações amorosas homossexuais. Nesse sentido, é necessário verificar como o romance de amor define, cria e descreve as relações sexuais e afetivas que se desenrolam entre estes sujeitos. Desta forma, interessa-nos detectar as diferentes configurações discursivas segundo as quais os sentidos do homoerotismo masculino vêm sendo pensados e problematizados neste espaço ficcional. Para tal, partimos de pressuposto de que a experiência homoerótica

\footnotetext{
6 Os próprios romances sentimentais presentes no mercado cultural contemporâneo são alvo de pesquisas escassas. Porém, os trabalhos de Andrade e Silva (2011, 2014, 2015, 2018 a), Andrade e Feitosa (2018b), Leão (2017, 2016) destacam-se neste incipiente campo de análise.
} 
desta literatura é indissociável dos padrões heteronormativos que constituem a tradição do gênero em questão. Nesta perspectiva, é preciso investigar a maneira como esta literatura se articula com as ideias de heterossexualidade, masculinidade e feminilidade que formatam o romance sentimental desde seu nascimento, em meados do século XIX até a contemporaneidade.

Neste contexto, metodologicamente, utilizamos como corpus de análise quatro obras de autores de sucesso de grandes editoras estrangeiras que fazem parte dos projetos de comunidades de leitores que marcam presença na internet. Portanto, selecionamos Quando o coração chama, de Leiland Dale (2014); Coração da Montanha, de Leiland Dale (2015); Reivindicando o cupido, de Jaxx Steele (2014) e Verdade seja dita, de Tansim Baker (2018). Todas estas obras são romances sentimentais exemplares, produzindo uma narrativa que dá relevo a experiências afetivas e sexuais que são assimiladas pelo mercado como "histórias de amor gay" e assim são entendidas pelos integrantes destas comunidades.

Esta constatação aparece com clareza logo após o aparecimento dos créditos desses ebooks artesanais, numa seção intitulada "Revisoras Comentam", ou em algumas obras, "Comentários da Revisão", na qual as revisoras, tradutoras, formatadoras e disponibilizadoras da obra emitem juízos de valor sobre a "qualidade" da narrativa, a construção "perfeita" dos mocinhos da história, o desenvolvimento "emocionante" do enredo ${ }^{7}$. Nesta seção, vemos que, independentemente desses romances terem protagonistas homossexuais masculinos, o que se ressalta nos comentários é a sensibilidade, romantismo, ardor, sensualidade com que a história é contada, reforçando as etiquetas usuais do gênero: a atração sexual que desponta como um elemento único e especial entre o casal de amantes, os obstáculos que impedem a união dos enamorados e a emoção que a trama deve destilar em seus leitores, como destacado nas transcrições selecionadas:

Regina: Essa história é tão doce. Ela começa onde a outra parou e conta a história de Jasper, o irmão do moçinho da história anterior, com Seth, o proprietário da fazenda Hart. A atração é instantânea, mas Seth tem um segredo, e não sabe se pode confiar em Jasper, pois já foi traído antes. (...) A autora soube conciliar o drama, a tensão, e deixar o sexo quente para o final. Recomendadíssimo! (DALE, 2015, p. 01).

\footnotetext{
${ }^{7}$ Ressaltamos que este ofício, nas comunidades de democratização de leitura, é realizado eminentemente por mulheres. A inexistência, em nosso levantamento empírico para este trabalho, de romances protagonizados por mulheres lésbicas, bi ou transexuais não só reforça a característica estrutural de menor visibilidade destas identidades sexuais e de gênero abrigadas no dito mercado LGBT, como sugere uma identificação dessas leitoras e tradutoras pela masculinidade encarnada em seus protagonistas.
} 
Beatriz: Uma história tão romântica! Apesar da intolerância que existe contra um casal de homens, é uma história leve, onde os dois não conseguem ficar longe um do outro, e quando se separam sofrem tanto. Mas uma coisa é certa, são quentes juntos. É de fazer suar, acelerar a frequência cardíaca... não dá pra saber qual dos dois é mais gostoso. (BAKER, 2018, p.01).

Assim, não há dúvidas, pelos comentários acima descritos de que os romances homoeróticos se inserem nas estratégias discursivas comuns ao gênero sentimental. Neste contexto, exploramos a seguir como se constrói a relação entre os protagonistas elaborada pelas estratégias discursivas do texto, fundada em uma tradição heteronormativa, de que forma as tramas homoeróticas desses romances são desenvolvidas e em que medida o enredo, os cenários e personagens encenam aspectos específicos ligados às experiências associadas às homossexualidades, reafirmando, transformando ou hibridizando as normas deste gênero literário. Em outras palavras, o que é, efetivamente, um romance sentimental de amor homoerótico?

\section{Masculinidades, "armário" e modelos (hetero)normativos}

Os romances sentimentais vão se caracterizar por centrarem seu relato no encontro amoroso e em suas dificuldades de realização. Existem, assim, três características em comum a todos os romances sentimentais: um casal protagonista, um conflito que move a narrativa e a certeza de um final feliz.

O casal protagonista dos romances sentimentais homoeróticos tem profissões típicas da classe média, porém, sempre em posições de destaque na sociedade, é competente e bemsucedido. Aqui, as determinações de gênero se unem claramente às de classe. Eles são advogados, policiais, fazendeiros, artistas de forma geral, desportistas, fazendeiros, veterinários, políticos famosos. Os lugares que frequentam, os hábitos de consumo, o estilo de vida, em tudo, acompanham sua classe social. Eles frequentam centros comerciais, vão a festinhas de trabalho, pedem comida com entrega em domicílio, gostam de bons restaurantes, cinemas e peças de teatro. E têm por hábito, para a paquera ou para o encontro sexual fortuito, estarem presentes sempre em bares gays ${ }^{8}$.

\footnotetext{
8 Ao longo do século XX, bares frequentados por sujeitos LGBTs constituíram-se em locais de referência para a construção de relações de sociabilidade, flerte ou reivindicações de políticas afirmativas. É ilustrativo o caso do bar Stonewall Inn, situado em Nova York e epicentro de protestos de trans, lésbicas, bissexuais e gays em 1969, como centro de narrativas das últimas décadas acerca da mobilização dos movimentos LGBTs nos Estados Unidos e globalmente. Não obstante a necessidade de leituras críticas que lembram a existência de outros sítios importantes de socialização e de atuação coletiva anteriores. Achilles (1998 [1967]), na década de 1960, já discorria sociologicamente sobre a relevância do "bar homossexual" como uma "instituição" para as comunidades, subculturas ou grupos "desviantes".
} 
$\mathrm{Na}$ descrição física, há uma grande ênfase nos estereótipos tradicionais de masculinidade. Os protagonistas são altos, fortes, musculosos, bronzeados, extremamente bonitos e sexys, caucasianos, com cores de olhos e cabelos variáveis. Valorizam-se, pois, representações reiterantes de uma "masculinidade dominante", nos termos de Gilmore (2008), caracterizada por elementos de "heroísmo", "coragem", do "homem protetor", "competitivo" e, não obstante, marcado pela "virilidade" e pela "potência sexual".

Max era esteticamente perfeito. Seus ossos da face eram altos e esculpidos, os lábios em forma de arco e uma cor linda avermelhada, e sua mandíbula era forte e quadrada. Seus cabelos e olhos escuros podiam parecer viciosos ou sensual, dependendo de qual roupas Daniel colocava e do humor por trás de seus olhos. (STEELE, 2014, p. 06).

Devon tinha o corpo de um nadador. De onde ele estava Greg podia ver a definição do músculo do tórax de Devon debaixo de sua camisa. Os olhos de Greg continuavam voltando para os lábios carnudos e deliciosos de Devon. Eles eram perfeitamente cor-de-rosa e imploravam para serem completamente saqueados. Uau. (DALE, 2014, p. 21).

O homem era magnífico com aqueles olhos verdes deslumbrantes, ombros largos, e músculos duros evidentes debaixo de sua camisa apertada. Ele se lembrou de olhar para as mãos sensuais do homem do trabalho duro. 0 pensamento daquelas mãos o tocando quase o teve derramando em suas calças. (DALE, 2015, p. 23).

No entanto, quanto ao temperamento, há variações, porém, elas seguem os padrões de heteronormatividade. Os protagonistas são sempre corajosos, bem-educados e corteses. Um deles é protetor, controlador, másculo e pró-ativo na relação. Ele é seguro, tranquilo, dinâmico, reproduzindo claramente os atributos da masculinidade usuais. 0 outro é cheio de cuidados, afeto, inseguranças, suscetibilidades e sensibilidade. Este fato, porém, mais do que desestabilizar ou pôr em xeque modelos tradicionais de masculinidade, reforça em um dos protagonistas a imagem do homem "protetor". E mesmo quando os protagonistas são apresentados como dóceis, civilizados, também o são "domados", sem abertura a transgressões, tratando-se majoritariamente de figuras quase sempre higienizadas:

Greg respirou profundamente e sua boca ficou seca enquanto olhava naqueles olhos cor de avelã. A tristeza refletida neles destacaram seus instintos protetores. Ele queria agarrar o homem e segurá-lo perto. (DALE, 2014, p. 19).

"Sim, eu sei que não era a favor de um novo veterinário na cidade, mas quando eu o encontrei pela primeira vez, eu só queria tomá-lo em meus braços e o proteger do mundo, sabe?” (DALE,, 2014, p.51). 
Aqui, a verve melodramática, o engajamento emocional, a extravagância emotiva comuns ao gênero aparecem com clareza. Não é à toa que esta categoria de romance é nominada como sentimental, pois é a expressão excedida dos sentimentos e não o desenrolar da ação que prende a curiosidade do leitor e garante a fidelidade ao gênero. Como bem lembra Souza Junior (2010), o estímulo à atenção do leitor, em qualquer narrativa ficcional, depende de estratégias discursivas que o seduzam. Assim, nestes livros, este fascínio está relacionado a sensações usualmente descritas como palpitações do coração, a tremulação das mãos, a emoção que rouba o "colorido das faces" de suas personagens centrais. Neste sentido, o apelo erótico desses romances busca se construir, inexoravelmente, por meio da dimensão das emoções. Neste gênero, o erotismo só tem sentido se engajado em emoções que atingem diretamente o coração e a alma das personagens:

A luz dançou no escuro de seus olhos, mas havia lá tristeza ...e as lágrimas não derramadas. Max lambeu os lábios e olhou para ele por um tempo até que finalmente falou. - Danny, eu, eu não quero ficar sozinho hoje à noite. Eu estou cansado de estar sozinho. Posso passar a noite com você? Seus olhos estavam arregalados de surpresa e a sua voz quebrada pela emoção. Uma lágrima caiu lentamente ao lado de seu rosto quando ele piscou. A visão da lágrima correndo cortou o coração de Daniel. (STEELE, 2014, p. 2223).

Ele não tinha outras palavras, isso estava além delas. Então, aparentemente, lágrimas atingiram-no na parte de trás do pescoço. Patrick sorriu e o sono reivindicou os dois. Ele puxou a mão de Liam em torno de seu corpo e estendeu a mão para o seu coração, exatamente onde ele estava concebido para estar. (DALE, 2015, p. 100-101).

Todavia, em geral, nos romances com casais heterossexuais esta extravagância emotiva se revela quase sempre como uma característica da personagem feminina. São as mulheres que empalidecem e emudecem, que derramam lágrimas, que perdem a respiração em um momento de extrema emoção, que secam a boca, que absorvem clarões gelados ou quentes nos olhos, que ruborizam. São as protagonistas femininas, nas relações heterossexuais descritas na literatura sentimental, quem lutam, sem sucesso, sempre por conter as emoções que extrapolam e repercutem em seus corpos. No caso dos romances sentimentais de temática gay, em geral, os protagonistas reverberam características que se relacionam intensamente ao universo construído historicamente como pertencente ao feminino no tocante à vivência das emoções.

Em geral, a história se inicia com um conflito de ordem sentimental que assombra um dos protagonistas ou os dois: uma doença recente na família que destruiu a relação anterior 
de um dos protagonistas; a mudança ou perda de um emprego que o incentiva a mudar radicalmente de vida; um segredo a ser desvendado; um amor antigo sem esperanças de vingar; um desafio emocional ou físico difícil de ser superado sem a intervenção de um amante; dois enamorados que estão em situações profissionais eticamente proibitivas. Nestes romances sentimentais homoeróticos, o conflito que gera o enredo segue fielmente as normas e regras do gênero literário.

A sociedade ali descrita, portanto, é basicamente semelhante aos romances heterossexuais contemporâneos idealizados. Os conflitos que vivenciariam seriam, assim, muito próximos àqueles que se estabelecem nos romances heteronormativos. Não há quase nenhuma referência a situações de preconceitos, marginalização, homofobias sentidas ou presenciadas pelos protagonistas. Trata-se, obviamente, da construção de uma sociedade imaginária na qual os homens gays já teriam sido plenamente incorporados ao social. A exclusão social, a rejeição, o abandono estariam presentes na periferia do romance, em outras cidades, distintas daquela onde a história se desenrola.

O povo de Bridger não era contra homossexuais, de fato eles eram o oposto total. A maior parte das pessoas que vivem nesta pequena cidade veio de famílias quebradas e muitos foram expulsos de suas casas depois de revelar sua preferência sexual. (DALE, 2015, p. 18).

Em geral, nestes romances, ser "assumidamente" gay não é uma questão social a ser equacionada. Em raras obras, o conflito entre o casal de amantes se revela porque um dos parceiros não deseja, por uma série de razões de ordem profissional ou familiar, "sair do armário". Este é o caso de "Verdade seja Dita". Porém, de qual "armário" estamos falando? A que metáfora estamos fazendo referência?

Sedgwick (1990) entende o "armário" como um regime de conhecimento, estruturado em torno do "saber" e do "não saber". Feitosa (2013) lembra que é necessário não "essencializar" o armário, uma vez que tanto sua estruturação como os efeitos deste "regime de conhecimento" não seriam uniformes, mas atravessados por estratégias diversas e cambiantes, tanto no interior de diferenças e assimetrias culturais e geográficas como das relações de classe, raciais, gênero em suas realidades locais. Miskolci (2012), por seu turno, alerta para a necessidade de superar uma visão que considera o armário como atemporal, uma vez que regimes de visibilidade são históricos e, como tais, passíveis de transformação com o tempo e variáveis segundo particularidades culturais. 
Nesse sentido, eventuais conflitos que poderiam advir no interior desta gramática do "saber" ou "não saber" - observáveis nas reiterações das personagens, nas situações sociais encenadas e na visão de mundo dos protagonistas - não se reverberam, nesses romances, em uma dimensão mais complexa. Na trama de Verdade seja Dita, um dos parceiros pressiona o outro para "sair do armário" a fim de provar o nível de comprometimento do amado com a relação. 0 discurso apresentado recai sobre o fato de que os homens gays que não saem do "armário", revelando sua orientação sexual ao mundo, seriam rechaçados por aqueles que se assumem. Estes, popularmente conhecidos como "enrustidos", são criticados pelos parceiros que preferem revelar o "segredo".

Então Liam virou os olhos azuis-aço sobre ele, toda a diversão se foi. "Ela não sabe que você é gay?" A garçonete tinha que escolher aquele momento para chegar com a comida. Ela colocou os pratos cheios para baixo na frente deles e saiu com pressa. Pobre mulher. Patrick olhou para o prato de massa azeda, ovos, bacon, batatas fritas, salsichas e tomates. "Isso parece ótimo." Liam fez um barulho impaciente em sua garganta e pegou sua faca e garfo. "Você está brincando comigo? Como pode não lhes ter dito até agora?" Ele deu de ombros e pegou um pedaço de bacon crocante. "Eu simplesmente não disse. Não há necessidade." "Não há necessidade? É parte de quem você é. Você não tem nenhum autorrespeito?" Patrick estava ficando um pouco chateado agora. Quem era Liam para dizer-lhe como viver sua vida? "Liam, olha, eu vou chegar a contar isso. Eu sei que vou ter que contar, eventualmente, mas meus pais irão ter um ataque. Então deixei passar". (BAKER, 2018, p. 28).

No entanto, até uma situação passível de desdobramentos conflituosos é, na trama, resolvida de forma harmônica. 0 "medo" da personagem de ser rechaçada em seu ambiente de trabalho ou em sua vida doméstica, por seus pais ou familiares, prova-se inócuo. 0 coroamento de seu sucesso como "gay assumido" revela-se num evento familiar, um casamento de uma prima, quando a revelação é aceita como natural e óbvia. No ambiente de trabalho, as reações positivas também se avolumam, surpreendendo a personagem. Nesse sentido, prevalece a valoração (e naturalização) do "assumir-se" como crucial para o "autorrespeito" e para a realização pessoal bem como essencial para a assunção de um modo de vida mais honesto, transparente (consigo e com o parceiro) ou verdadeiro.

Jackson sorriu conscientemente. "Eu nunca o vi ao telefone antes, agora o verifica a cada dois minutos. Quem é a garota que não retorna para você?" Patrick se endireitou na cadeira, seu primeiro desafio desde seus pais. "Liam realmente é o seu nome. Eu meio que fodi as coisas um par de semanas atrás, e ele não me envia uma mensagem de volta." Ele olhou nos olhos verdes de Jackson, desafiando-o a desviar o olhar. Ele tossiu um pouco. "Desculpa cara, espero que resolva o problema." "Eu também, Patrick." 
Nicola, a cabeça vermelha bonita que se sentava ao lado falou, simpatia escrito por todo o rosto. "Eu sou muito boa em desculpas, se precisar de algum conselho. 0 que aconteceu?" Ele olhou ao redor da sala, esperando ver censura, horror, até mesmo nojo. Em vez disso, viu simpatia e surpresa. (BAKER, 2018, p.77).

Quando o casal protagonista se conhece, assim como nos romances heteronormativos, a atração sexual é intensa. O desejo vai ter um papel importante no desenvolvimento da narrativa sentimental. Neste sentido, o apelo à paixão toma o lugar central na história. Nela, o amor só é legitimado pela intensidade arrebatadora, cuja expressão oferece a garantia de legitimidade da experiência amorosa. Configura-se, assim, uma nova modalidade do amor sentimental, a do desejo à primeira vista. Ele ocorre simultaneamente ao amor à primeira vista. Quando se conhecem, os amantes gays se entregam à paixão de forma desenfreada e incontrolável.

Greg se sentiu como um adolescente apaixonado. Jordan olhava especulativamente sorrindo para eles. Greg sentiu uma atração imediata por Devon. Ele não conseguia entender por que ele teve este sentimento engraçado dentro de que fez seu coração virar. (DALE, 2014, p. 20).

O momento que seus olhos se encontraram, a respiração de Devon ficou presa em sua garganta. Ele teve que se controlar para não gemer em voz alta. Então, sentando na frente de Greg fez seu pau ficar duro em segundos, empurrando contra o zíper de sua calça. (DALE, 2014, p. 22).

A atração, jamais experenciada de uma forma tão intensa, toma conta da narrativa. As descrições do ato sexual são detalhadas, minuciosas, quebrando com as rotinas cotidianas. 0 casal não trabalha, não interage com o entorno social, não se alimenta ou opta por algum lazer ou entretenimento, apenas tem relações sexuais prazerosas, inovadoras, plenas, perfeitas. A esse respeito, Giddens (1993) afirma que o amor apaixonado é marcado por uma urgência que o coloca à parte das rotinas da vida cotidiana. Os romances homoeróticos, assim, em nada se distinguem da forma como o sexo é descrito nas relações heteronormativas.

Os livros sentimentais têm a tendência de revelar o ato físico do amor como apaixonadamente perfeito. Os romances estudados reiteram essa característica. 0 casal compreende que está completamente apaixonado e em estado de luxúria. 0 intercurso sexual toma uma dimensão totalmente diferente das suas experiências anteriores. 0 sexo parece nunca ser suficiente para "apagar o fogo" que os está consumindo. Esta descoberta validaria a sinceridade do amor que sentem: 
Devon ajoelhou lentamente enquanto beijava e lambia a distância todo peito e estômago de Greg. Ele apertou seu nariz nos pelos púbicos de Greg, sentindo seu cheiro masculino que o dirigiu louco com luxúria. Devon lambeu a distância toda da seta até a ponta, capturando uma gota de líquida em sua língua. 0 gosto explodido na língua de Devon. Não era doce, nem era azedo, era só perfeito. (DALE, 2014, p. 22).

Daniel finalmente falou, mas não pôde olhar nos olhos de Max. — Eu não quero que você saia. Eu te amo. Eu sempre amei você. Não me lembro de não te amar. Não apenas como um amigo, mas como um amante. (STEELE, 2014, p. 38).

A relação ideal, entre os protagonistas gays, tal como para os héteros, é a que foca na parceria sexual perfeita. $O$ sexo não é visto, para os amantes, como um ato de voracidade egoísta, mas como um prazer mútuo. A cada vez que têm relações sexuais, a atitude dos protagonistas, antes plenamente sexual, começa a se transformar, uma vez que, passam a ver um ao outro como seres únicos e não mais como uma de suas conquistas amorosas. 0 princípio da individualidade que governa o amor romântico se concretiza na narrativa.

\footnotetext{
Devon estava deitado na cama ao lado de Greg dormindo. Devon nunca teria imaginado que teria um cowboy para chamar de seu. Ele só ficou ali deitado em silêncio o vendo dormir. Eles passaram a noite inteira fazendo amor. Devon deveria estar esgotado como seu noivo, mas ele não conseguia dormir, ele não estava cansado. (DALE, 2014, p. 80).

Ele tinha esse ato feito várias vezes em sua vida, mas ele jamais esqueceria este, não porque ele era incrível, mas porque Max estava fazendo isso (...) Os beijos suaves que Max deixou no pescoço de Daniel eram doces, carinhosos, e quase amorosos. (STEELE, 2014, p. 31-33).
}

O sexo perfeito, em ambas as narrativas, seja hetero ou homoerótica, revela um momento de contentamento na relação ainda que não liberte o casal amante das tensões em suspenso que compartilham. A descrição minuciosa de imagens eróticas reforça a ideia de que o amor verdadeiro leva à felicidade. A culminação de seu amor se expressa pelo ato sexual a partir do qual a união é completamente estabelecida. A paixão no ato do amor mostra que o casal é capaz de resolver seus problemas e diferenças, em resultado, eles começam a confiar um no outro e, portanto, estão aptos a resolverem os conflitos que permeiam a relação.

Todavia, os romances heteronormativos nunca deixam de relacionar, no melhor estilo do amor romântico, o sexo à procriação. 0 cenário mais comum, nestes romances, como resultado da paixão é, com certeza, o da gravidez. Mesmo na primeira década do novo 
milênio, as protagonistas relutam em utilizar meios contraceptivos tais como camisinhas ou pílulas (GARDNER;MACDONALD;DIEKAMN, 2000). Nesses romances, o uso do preservativo é um mero controle de natalidade, uma vez que, o universo das doenças sexualmente transmissíveis não faz parte da narrativa. 0 resultado disso tudo é que, nos romances heteronormativos, o sexo perfeito é aquele no qual o preservativo não está presente.

Este não é o caso da literatura sentimental homoerótica. 0 uso do preservativo é uma constante em todas as relações sexuais descritas. Ora é naturalizado como parte das relações entre homens homossexuais, sendo um elemento de composição da narrativa erótica ao se descrever detalhadamente a prática sexual, ora é interiorizado como parte de uma pedagogia sobre a prática de um sexo "seguro", protegido:

Greg agarrou o lubrificante e apertou um pouco sobre seus dedos. Girando seu dedo em torno do buraco apertado, alisando, ele deslizou um dedo dentro e olhando para o rosto de Devon o tempo inteiro. A necessidade e desejo puros nos olhos de Devon o fizeram gemer. "Mais!" Devon implorou para ele. Ele deslizou outro dedo dentro de Devon, o estirando. Greg agarrou um preservativo e rasgou o pacote com seus dentes. Retirando seus dedos do buraco apertado de Devon, ele deslizou o preservativo e apertou um pouco mais de lubrificante em cima de sua seta dura, alisando a si mesmo. (DALE, 2014, p. 39).

"Parece que você pode." Liam riu, puxando para trás e segurando os quadris de Patrick. Liam apertou a cabeça de seu pênis em sua entrada e Patrick sentiu o toque do látex. "Obrigado pela proteção." Ele suspirou, deixando cair sua parte superior do corpo para baixo em cima da cama. Ele ainda estava flutuando em êxtase. (BAKER, 2018, p. 11).

Uma característica típica, porém, dos romances homoeróticos, não presentes nos heteronormativos, são as constantes referências à masturbação. Os protagonistas desses romances, ao se sentirem excitados pela presença ou lembrança de suas amadas, costumam tomar vários banhos gelados ou praticar exacerbadamente exercícios físicos. A masturbação parece não condizer com os ideários românticos-apaixonados ali apregoados. Os protagonistas gays, ao contrário, praticam a masturbação com frequência. Cabe ressaltar, contudo, que tal prática é suspensa quando um dos personagens inicia a relação amorosa com o outro protagonista, ou seja, quando encontra o amor romântico.

Suas mãos roçaram seus mamilos sensíveis fazendo eles imediatamente duros quando as imagens eróticas de Greg inundaram sua mente. Devon imaginou Greg no chuveiro com ele, o tocando, o ensaboando. Seu pênis imediatamente tomou conhecimento e endureceu quando a fantasia erótica pegou em sua mente. (DALE, 2014, p. 26-27). 
Seus dedos enrolaram em volta da carne macia do pênis amolecido. Ele moveu-os em um movimento ascendente, formando um filme de sabão branco. Repetindo o movimento fez seu membro engrossar rapidamente, excitando-o ainda mais. Daniel largou a toalhinha, plantou os pés no tapete de borracha claro, e se inclinou para a frente com a palma da mão na parede à sua frente para se equilibrar. Imaginando Max em sua mente. Daniel sorriu. (STEELE, 2014, p. 14).

Porém, como todo bom romance sentimental, o ideário que está por detrás do sexo apaixonado é o do amor romântico. Assim, não é qualquer pessoa que destilará a felicidade, é a predestinada, aquela especial que solucionará todas as questões, que preencherá o seu mundo interior, que unificará dois seres, completando-os para sempre. Os protagonistas são almas gêmeas e, portanto, uma fração de um ser humano para o qual existe um complemento. Dessa forma, quando um deles encontra o outro que é precisamente a outra metade de si, cada um é tomado por uma extraordinária emoção, completa e intensa.

\footnotetext{
"Ele não era a pessoa certa para você," ela começou e tomou outra respiração para continuar. "Quando um homem chegar e olhar para você como se você fosse seu mundo... então você saberá que encontrou a pessoa certa." Ele olhou para ela com lágrimas escorrendo por suas bochechas. (DALE, 2014, p. 5).
}

Durante a próxima semana e meia, Devon caminhou ao redor de uma névoa de felicidade e felicidade. Ele não podia parar de pensar sobre sua noite com Greg. (DALE, 2014, p. 47).

É este ideário que conjuga sexo e amor, propondo um amor recíproco e indissolúvel que orienta a trama. A satisfação esperada é emocional, além de sexual. Não é à toa que a relação entre os enamorados não pode ser definida apenas pelo prazer na relação sexual, ela também deve se mostrar plena de companheirismo, intimidade, segurança afetiva, parceria mútua, solicitude, ternura, carinho e compreensão. Assim, se o componente sexual é percebido como essencial para o código amoroso, o amor sublime deveria, ao fim, predominar sobre o ardor sexual.

Desde então, eles se encontraram para almoçar e jantaram várias vezes e se falaram por telefone quase todo dia. Ele sorriu quando recordou a outra noite quando ele adormeceu com o telefone ainda agarrado a sua orelha. Devon estava caindo apaixonando pelo áspero cowboy. (DALE, 2014, p. 47).

Mas a melhor parte disso tudo era dormir e acordar embrulhado nos braços de Greg. Greg deu a ele muito mais que um lugar para ficar. Ele deu o suporte que precisava durante um tempo difícil em sua vida e que não tinha mais ninguém. (DALE, 2014, p. 67). 
O amor descrito nestes romances torna possível a posse completa do outro. Os protagonistas devem pertencer um ao outro de forma total e inexorável. Para tal, a exclusividade, a fidelidade, o compromisso seriam essenciais. Os dois seres apaixonados devem viver apenas um para o outro.

Lá estava ele, deitado ao lado do homem que ele amava com todo seu coração. Um homem, que ele conhecia e se sentia da mesma maneira que ele. Ele não precisava dizer nada, mas Greg olhava para ele como se ele fosse seu mundo. Ele era único. Ele sabia que sua mãe concordaria. (DALE, 2014, p. 80).

Patrick empurrou com mais força, mais rápido. Amor e posse que nunca havia sentido fluía sobre o seu coração e alma. Esta pessoa lhe pertencia, tanto quanto ele pertencia a Liam. "Eu te amo tanto, você não tem ideia. Você é meu, eu sou seu. Nunca vou deixar você ir." (BAKER, 2018, p. 64-65).

Por último, para coroar o ideário romântico, a relação tem que ter caráter de permanência, o "felizes para sempre" deve estar presente. Não há mais inseguranças, indecisões, dúvidas, todos os questionamentos foram resolvidos. 0 amor romântico apaixonado destilado na trama é o que se perpetua, com a mesma intensidade, da mesma forma por toda a vida.

"Pela primeira vez em minha vida, eu verdadeiramente sinto, realmente, feliz e completo. É tudo isso é por sua causa. Eu achei que eu podia me abrir com você, e dizer coisas que poucas pessoas sabiam sobre mim, sem ter medo que você iria embora". (DALE, 2015, p. 79).

Contudo, a finalização da narrativa só pode se estabelecer a partir do modelo burguês que orienta, mapeia e constrói o amor romântico. 0 casal gay acompanha os valores burgueses da união familiar. Neste caso, os filhos são substituídos por animais de estimação ou pelo recurso da adoção:

- Eu... eu quero uma família, Danny. Alguém para voltar para casa, um homem e um animal de estimação. Não um gato porém, eles são muito malditamente sorrateiros. Eu não gosto deles. Talvez um cachorro. Sim, eu gosto de cães. Enfim, você sabe o que estou dizendo, não é? (STEELE, 2014, p. 04).

Max riu e levou as duas mãos de Daniel na sua. - Aposto que você não pode dizer isso novamente, mas você está absolutamente certo. Eu sei. Foi você o tempo todo. Você é a família para qual eu quero vir para casa. - Tem certeza que isso é o que você quer, Max? Eu não tenho nenhuma intenção de 
desistir de você, no momento que estivermos juntos como um casal oficial, você sabe. (STEELE, 2014, p. 39-40).

Eu sei que isso é novo para você e, provavelmente, aterrorizante, mas adoro o seu filho. Ele é tudo o que tenho procurado ao longo dos últimos dez anos. $\mathrm{E}$, tanto quanto casamentos e bebês. Nós não falamos sobre isso. Nós estamos juntos apenas seis meses, mas quero uma família. Eu sempre quis adotar uma criança, que estaria de outro modo preso no sistema de assistência social e procurei isso. Por favor, não pense que vou deixar Patrick perder nada que uma boa vida deve ter." (BAKER, 2018, p. 90-91).

O modelo burguês de família impera, portanto, como desfecho tanto nas narrativas hetero como homoeróticas. A felicidade no amor, assim, só é possível, a quatro paredes, no interior da família nuclear sobre a qual filhos e animais domésticos compõem o ideal de harmonia, bem-aventurança e completude inerentes à literatura sentimental.

\section{Considerações finais}

A literatura sentimental homoerótica reproduz diversos princípios que configuram a gramática amorosa na heteronormatividade. Em diversos aspectos, esta literatura parece apenas se diferenciar da literatura sentimental tradicional pelo fato de os protagonistas serem homens gays. A procura por subversão, transgressão, militância em suas estratégias discursivas é, quase sempre, ineficaz. Esta literatura, como qualquer outro texto ficcional, porém, é alheia a essa lógica de "formação da consciência, juízo ou do espírito crítico", desvinculada em relação a todos os projetos políticos, incluindo-se aí também as formas que ressoam no ativismo LGBT que se nela encontra lugar é sempre de forma tangencial. Porém, como bem o lembra Barcellos (2006), ainda que, em sua origem, muitas obras literárias apareçam vinculadas a determinados projetos políticos, sua qualidade literária depende em boa parte da capacidade de transcendê-los e não de sua "ortodoxia" e fidelidade em relação aos mesmos.

A análise dos romances aqui realizada nos mostra que, no interior destas tramas, as situações encenadas, os modos como os perfis dos protagonistas são elaborados, os conflitos utilizados como ganchos das estórias e seus respectivos desfechos, muito mais do que subverter, tensionar ou reinventar as normas deste gênero literário, reforçam modelos idealizados tanto dos seus personagens como dos relacionamentos sexuais e amorosos, seguindo regras já estabilizadas como bem-sucedidas nas fórmulas dos romances dito sentimentais protagonizados por casais heterossexuais. 
Uma primeira aproximação ao universo destes romances revela como positiva a ampliação de certa visibilidade, neste campo da cultura de massa, de personagens e temáticas protagonizadas por homossexuais. Um olhar mais específico sugere, porém, que este segmento editorial está longe de questionar ou pôr em primeiro plano vivências e conflitos experienciados por sujeitos não-heterossexuais, privilegiando a importação ou transposição dos princípios que estruturam os romances sentimentais em geral.

Abre-se, notadamente, um nicho de mercado neste universo editorial de publicações populares, buscando fisgar tanto leitores homossexuais como, algo revelado nas comunidades de leitores analisadas, renovar o interesse de leitoras já fãs dos romances sentimentais padrões. Decorre daí que tais romances, exceto por uma ou outra situação específica a ser diluída e facilmente solucionada na estrutura de suas tramas, revelam-se essencialmente conservadores, no sentido de que tanto enquadram a representação das homossexualidades sob padrões (hetero e homo) normativos, não abrindo espaço para retratar outros modos de ser e viver, como focam na preservação das regras que escritores, editores, "revisores"/tradutores amadores e leitores atribuem a um bom e bem-sucedido "romance de amor".

\section{Referências}

ACHILLES, Nancy. The development of the homosexual bar as an institution. In: NARDI, Peter M. E SCHNEIDER, Beth E (eds). Social perspectives in lesbian and gay studies: a reader. Londres: Routledge, 1998 [1967].

ANDRADE, Roberta Manuela Barros de; SILVA, Erotilde Honório. A Pedagogia Social dos Romances de Amor dos "Tempos da Vovó". Tensões Mundiais, v. 11, n. 21, p. 251-274, 2018a.

ANDRADE, Roberta Manuela Barros de; FEITOSA, Ricardo Augusto de Sabóia. A cultura emotiva das comunidades virtuais de leitura de livros de amor. RBSE Revista Brasileira de Sociologia da Emoção, João Pessoa, v. 17, n. 51, p. 91-104, dezembro de 2018 b.

ANDRADE, Roberta Manuela Barros; SILVA, Erotilde Honório. A vida em cor de rosa: o romance sentimental e a ditadura militar no Brasil. Revista FAMECOS: Porto Alegre, Rio Grande do Sul, v. 17, n. 2, p. 41-48, 2010.

ANDRADE, Roberta Manuela Barros; SILVA, Erotilde Honório. Os romances sentimentais e a revolução digital: os processos de criação dos projetos de democratização da leitura nos livros do coração. Revista de Estudos da Comunicação, Curitiba, Paraná, v. 16, n. 41, p. 345$361,2015$. 
ANDRADE, Roberta Manuela Barros; SILVA, Erotilde Honório. Os Romances Sentimentais e suas Comunidades de Leitura. 0 público e o privado, Fortaleza, n. 24, p. 119-134, jul./set. 2014.

BAKER, Tansim. Verdade seja dita. (s.l): (s.ed), 2018.

BARCELOS, José Carlos. Literatura e homoerotismo em questão. Rio de Janeiro: Dialogarts, 2006.

COSTA, Jurandir Freire. A inocência e o vício: estudos sobre o homoerotismo. Rio de Janeiro: Relume-Dumará, 1992.

DALE, Leiland. Coração da Montanha. (s.l): (s.ed), 2015.

DALE, Leiland. Quando o pássaro azul chama. (s.l): (s.ed), 2014.

DIAS, Roberto Muniz. Editoras LGBTTT Brasileiras contemporâneas como registro de uma literatura homoafetiva. 2013. Dissertação (Mestrado em Literatura) - Programa de Pós Graduação em Literatura (POSLIT), Universidade de Brasília, Brasília, 2013.

FEITOSA, Ricardo Augusto de Sabóia. O Outing como questão: trânsito de práticas e conceitos. In: IV Seminário Internacional do Programa de Pós-Graduação em Sociologia da UFSCar, 2013, São Carlos. Olhares e diálogos sociológicos sobre as mudanças no Brasil e na América Latina. Anais [...] São Carlos: PPGS UFSCar, 2013.

GARDNER, Wendi L.; MACDONALD, M. E DIEKAMN, Amanda B. Love never having to be careful: the relationship between reading romance novels and save sex behavior. Psychology of Women Quarterly, v. 24, n. 2, p. 179-188, 2000.

GIDDENS, Anthony. A transformação da intimidade: Sexualidade, amor e erotismo nas sociedades modernas. São Paulo: Editora UNESP, 1993.

GILMORE, David. Culturas de la masculinidad. In: CARABÍ, Àngels e ARMENGOL, Josep M. (eds). La masculinidad a debate. Barcelona: Icaria Editorial, p. 33-46, 2008.

LEÃO, Andréa Borges. Fazer do velho uma novidade: as reinvenções dos best-sellers juvenis. Caderno CRH. Salvador, v. 29, n. 78, p. 463-476, set./dez. 2016.

LEÃO, Andréa Borges. Séries literárias juvenis: autoria e circulação da cultura. Revista Ciências Sociais Unisinos, São Leopoldo, v. 53, n. 1, p. 57-65, jan./abr. 2017.

MISKOLCI, Richard. A gramática do armário: notas sobre segredos e mentiras em relações homoeróticas masculinas mediadas digitalmente. In: PELÚCIO, Larissa (orgs). Olhares plurais para o cotidiano: gênero, sexualidade e mídia. Marília: Oficina Universitária, p. 35$55,2012$.

MITIDIERI, André Luis, CAMARGO, Flávio Pereira. Literatura, homoerotismo e expressões homoculturais. Ilhéus: Editus, 2015. 
PÉRET, Flávia. Homoafetividade e literatura na América Latina: dois escritores, duas vidas, narrativas. Revista Em Tese, Belo Horizonte, v. 16, n. 1, 2010.

SEDGWICK, Eve Kosofsky. Epistemology of the closet. Berkeley: University of California Press, 1990.

SOUZA JÚNIOR, José Luiz Foureaux de. Herdeiros de Sísifo: teoria da literatura e homoerotismo. Mariana: Aldrava Letras e Artes, 2010.

STEELE, Jaxx. Reivindicando o cupido. (s.l): (s.ed), 2014.

VALE, Antonio Peterson Nogueira do. 0 deleite na literatura: o erotismo e a pornografia no texto de Caio Fernando Abreu. In: XVIII Semana de Humanidades. Natal, 2012. Anais [...]Natal:UFRN, p. 01-08. Acesso em 21 nov. 2018.

\title{
Homoerotic narratives: sex, love and family in the pages of sentimental novels
}

\begin{abstract}
The article proposes an analysis of homoerotic sentimental novels, investigating them as devices for the elaboration of normative models of sexual and affective relationships played by male homosexual characters. From the critical reading of three novels representative of this fictional genre, the existence of distinctive marks in such "love romances" is questioned, the specifics in their plots and to what extent they fit or reinforce the grammars that govern this literary production of popular stamp. Thus, the aim is to understand the different discursive configurations on which the meanings of male homoeroticism are thought and problematized in this fictional space, a segment little explored both in literary studies and in the field of investigations in gender and sexuality.
\end{abstract}

\section{Keywords}

Sentimental literature; Homoerotism; Mass culture; Normativity; Masculinities

\section{Autoria para correspondência}

Nome: Roberta Manuela Barros de Andrade

E-mai: manubarrosster@gmail.com

Nome: Ricardo Augusto de Sabóia Feitosa

E-mail: ricardo.saboia@ufpe.br 


\section{Como citar}

ANDRADE, Roberta Manuela Barros de; FEITOSA, Ricardo Augusto de Sabóia. Narrativas homoeróticas: sexo, amor e família nas páginas dos romances sentimentais. Intexto, Porto Alegre, n.52, e-97153, jan./dez. 2021. DOI: http://dx.doi.org/10.19132/1807-8583202152.97153

Recebido em 03/10/2019

Aceito em 22/06/2021 